Pak. j. sci. ind. res. Ser. B: biol. sci. 2019 62B(2) 101-110

\title{
Seaweed Extracts Effectiveness against Selected Gram-negative Bacterial Isolates
}

\author{
Basel Saleh*, Laila Al-Hallab and Ayman Al-Mariri \\ Department of Molecular Biology and Biotechnology, Atomic Energy Commission of Syria, \\ P.O. Box 6091, Damascus, Syria
}

(received June 27, 2018; revised November 29, 2018; accepted December 4, 2018)

\begin{abstract}
Aqueous and six solvent extracts of four seaweeds Codium tomentosum (Chlorophyceae); Corallina mediterranea, Hypnea musciformis (Rhodophyceae), and Sargassum vulgare (Phaeophyceae) were screened for their antibacterial activity against 10 gram-negative bacterial isolates. Seaweeds crude extracts potent antibacterial activity have been evaluated based on zone of inhibition (ZI), minimum inhibitory concentration (MIC) and minimum bactericidal concentration (MBC) values as reported in many researches. Overall, aqueous algal extracts were non active against all tested isolates regardless examined seaweed species. It was noticed that ZIs were in the following order: $S$. vulgare $(17 \mathrm{~mm})$ against Acinetobacter baumannii and C. mediteranea $(17 \mathrm{~mm})$ against Salmonella typhimurium $>$ H. musciformis $(13 \mathrm{~mm})$ against Escherichia coli O:157 > C. tomentosum $(11 \mathrm{~mm})$ against $S$. typhimurium. Data revealed that the $S$. vulgare extracts showed the most inhibitory activity by showing the lowest $\mathrm{MIC}_{50}$ value of $0.08 \mathrm{mg} / \mathrm{mL}$ (methanolic extract against Shigella flexneri and hexane extract against E. coli O:157 isolate) and also the lowest $\mathrm{MBC}$ value of $1.00 \mathrm{mg} / \mathrm{mL}$ (methanolic extract against $S$. typhimurium, Serratia marcescens, $E$. coli O:157 and Brucella melitensis isolates; and also with ethanolic extract against $S$. marcescens and $E$. coli O:157 isolates). Future studies on the $S$. vulgare extracts are required due to their importance as a potent, promising and cheap source of bioactive compounds for antibacterial pretreatment.
\end{abstract}

Keywords: seaweed, antibacterial activity, zone of inhibition, minimum inhibitory concentration, minimum bactericidal concentration

\section{Introduction}

Bacterial pathogens caused loss of living organisms with different rate e.g. mastitis, abortion and upper respiratory complications diseases yielded by Escherichia coli and Pseudomonas aeruginosa pathogen, whereas, Salmonella sp. infection lead to diarrhoea and typhoid fever diseases (Leven, 1987; Jawetz et al., 1985; Boyd, 1955). Moreover, Acinetobacter baumannii multidrug resistance (MDR) has been reported worldwide causing human skin flora. It has been demonstrated that their occurrence in human skin and mucous membrane occur into over $43 \%$ of human population, where, it displayed different infection forms e.g. bacteremia, urinary tract infection, meningitis, wound and burn infections, and most importantly nosocomial pneumoniae, particularly in ventilated patients (Saleh et al., 2015; King et al., 2009). A. baumannii resistance to antibiotics and disinfectants and the capacity to survive desiccation, makes it as an important persistence pathogen (Srinivasan et al., 2009).

The emergence of resistant bacterial strain worldwide as a common phenomenon caused antibacterial

*Author for correspondence; E-mail: bsaleh@aec.org.sy therapeutic failure. Thereby, great challenge achieved to augment antibacterial efficacy based on natural sources such as plants and algae. These living organisms became efficient, cheap, and potent agent for inhibition of bacterial growth due to their richness in different bioactive compounds.

Macro and microalgae displayed efficient activity against bacterial isolates due to their richness in bioactive compounds and their occurrence worldwide encouraged the scientists to introduce them in pharmacological research as antimicrobial agents. Many reports indicated potential use of seaweeds for their antibacterial activity (Boujaber et al., 2016; Kausalya and Rao, 2015; Karthick et al., 2015; Sushanth and Rajashekhar, 2015; Chandrasekaran et al., 2014; Kavita et al., 2014; Elnabris et al., 2013; Jeyaseelan et al., 2012; Tajbakhsh et al., 2011; Rhimou et al., 2010; Ibtisam et al., 2009; Kandhasamy and Arunachalam, 2008).

Moreover, seaweed crude extracts or their purified compounds make them a promising source not only as antibacterial, but also as an antioxidant, anticoagulant, anticancer, antiviral, and anti-inflammatory effects (Perez et al., 2016). 
Bacterial isolates could be divided into gram positive and negative, among them, gram-negative bacteria as reported in literature were more resistant to algal crude extracts due to their cell wall structure (thickness) and their composition, preventing entry of inhibitory agents into the cell (Chandrasekaran et al., 2014; Kandhasamy and Arunachalam, 2008). For this reason, antibacterial activity of 4 seaweed species crude extracts collected from Syrian coast has been evaluated against 10 gramnegative bacterial isolates. Thereby, the most potent seaweed will be handled in the future as antibacterial agent for performance studies.

\section{Materials and Methods}

Seaweed sampling. Four seaweed samples of Codium tomentosum (Chlorophyceae); Corelline mediterranea and Hyphea musciformis (Rhodophyceae), and Sagassum vulgare (Phaeophyceae) were collected from the Syrian coast of the Mediterranean Sea at $5 \mathrm{~km}$ North Lattakia - Syria (Latitude 35 $33^{\prime} 786^{\prime \prime} \mathrm{N}$ and Longitude $\left.38^{\circ} 29^{\prime} 766^{\prime \prime E}\right)$. Seaweed identification was done by taxonomical study in the Division of Plant Biotechnology at the AECS in Damascus-Syria. Seaweed samples were harvested by hand with disposable gloves and washed with seawater followed by two successive washings with double-distilled water. Samples were transfered to Whatman filter papers for elimination attached of water and acceleration their drying. Seaweed samples were shade dried for two weeks, powdered by special electric mill and stored separately in polyethylene bags until analysis.

Seaweed crude extracts preparation. Crude extracts of the C. tomentosum, C. mediterranea, $H$. musciformis and $S$. vulgare seaweeds were prepared using aqueous and six solvents (methanol, ethanol, chloroform, acetone, ethyl acetate and hexane) as previously reported in many investigations. One gram of shade-dried powdered seaweed materials were subjected to extraction in 100 $\mathrm{mL}$ solvent, until complete solubility. Then, the extracts were filtered with Whatman filter papers. Extracts were kept at laboratory temperature for $2 \mathrm{~h}$ to evaporate the solvent. All extracts were then kept in tightly fitting stopper bottles and stored in $4^{\circ} \mathrm{C}$. The concentration of extract was considered $10 \mathrm{mg} / \mathrm{mL}$.

Tested microorganisms and growth conditions. Ten pure gram-negative bacteria clinical isolates of Salmonella typhimurium, Serratia marcescens, Escherichia coli: O: 157, Proteus vulgaris, Acinetobacter baumannii, Brucella melitensis, Pseudomonas aeruginosa, Klebsiella pneumoniae, Shigella flexneri and Vibrio cholerae were obtained from the Microbiology and Immunology Division, Department of Molecular Biology and Biotechnology of Atomic Energy Commission of Syria (AECS) in Damascus Syria. Culture was maintained at $37^{\circ} \mathrm{C}$ on $2 \mathrm{YT}$ agar (peptone, $16 \mathrm{~g} / \mathrm{L}$; yeast extract, $10 \mathrm{~g} / \mathrm{L} ; \mathrm{NaCl}, 5 \mathrm{~g} / \mathrm{L}$; agar, $13 \mathrm{~g} / \mathrm{L}$ [Difco, BD, Spars, MD]); and incubated for $24-48 \mathrm{~h}$. Prior to antimicrobial sensitivity test, 0.2 $\mathrm{mL}$ of overnight culture of each organism was dispensed into $20 \mathrm{~mL}$ of sterile Mueller Hinton Broth (Hi-media Laboratory Pvt. Ltd., Mumbai, India) and then incubated for about 18-24 $\mathrm{h}$. The bacterial microorganisms were suspended in a sterile Phosphate-Buffered Saline (PBS). Bacterial abundance in PBS was screened by recording the optical density (OD) at $590 \mathrm{~nm}$, to standardize the cultures to approximately $106 \mathrm{CFU} / \mathrm{mL}$ (Saleh et al., 2015). The exact counts were assessed retrospectively by viable counts on $2 \mathrm{YT}$ agar plates.

Antibacterial activity assay. The disc-diffusion test. The disc-diffusion test was carried out for monitoring seaweed antibacterial inhibitory effect and Ciprofloxacin $(10 \mathrm{mg} / \mathrm{L})$ (Bayer, Istambul, Turkey) antibiotic was used as a standard drug control for seaweed antibacterial effect (Saleh et al., 2015; Bauer et al., 1966). The sterilized discs filter paper (Whatman no. 1 of $6 \mathrm{~mm}$ diameter) were inoculated with $100 \mu \mathrm{L}$ of extract dilutions $(10 \mathrm{mg} / \mathrm{mL})$ and reconstituted in minimum amount of solvent were applied over each of the culture plates previously cultivated with the $106 \mathrm{CFU} / \mathrm{mL}$ cultures of bacteria. Bacterial cultures were then incubated at $37^{\circ} \mathrm{C}$ for $18 \mathrm{~h}$, whereas, paper discs were inoculated with $20 \mu \mathrm{L}$ of a solution of $10 \mathrm{mg} / \mathrm{L}$ of Ciprofloxacin were used as standard drug. Negative control was achieved using solvents (final concentration of the solvent in the highest concentration of seaweed extracts was tested). Antibacterial inhibitory effect was determined by measuring the zone of inhibition $(\mathrm{mm})$ appeared around each paper disc. For each extract, duplicate trials were conducted against each microorganism.

Minimum Inhibitory Concentration (MIC) and Minimal Bactericidal Concentration (MBC) Determination. Microdilution broth susceptibility assay was performed as previously described by Rios-Duenas et al. (2011). Three replicates of serial dilutions of seaweed extracts $(50 \mathrm{mg} / \mathrm{mL})$ or of antibiotic $(128$ $\mathrm{mg} / \mathrm{L}$ ) were prepared in LB broth medium in 96-well microtiter plates, using a range of concentrations for 
aqueous and six solvents extracts of each examined seaweed species from 0.166 to $40 \mu \mathrm{L}$ per well. One hundred microlitres of freshly grown bacteria standardized at $106 \mathrm{CFU} / \mathrm{mL}$ in LB broth were added to each well. Positive control was prepared with the same conditions but without extract. As for negative control, it was also made with the same conditions but without adding the bacteria. The plate was then incubated with shaking for $24 \mathrm{~h}$ at $37^{\circ} \mathrm{C}$. The lowest concentration that completely inhibited visual growth was recorded and interpreted as the $\mathrm{MIC}_{50}$.

Whereas, $\mathrm{MBC}$ was determined by plating $0.010 \mathrm{~mL}$ from the wells showing no visible growth on MuellerHinton agar plates (Oxoid) and incubating for 18-24 h at $37^{\circ} \mathrm{C}$. The $\mathrm{MBC}$ was defined as the concentration at which there was a $99.9 \%$ reduction in CFU compared with the original inoculum.

Statistical analysis. All statistical analysis were performed using Graphpad Prism6 programming at the $5 \%$ level of significance $(p=0.05)$. All tests were performed in triplicates and mean values are presented as mean $\pm \mathrm{SD}$.

\section{Results and Discussion}

Zone of inhibition (ZI) assay. Antibacterial activity of 4 seaweed crude extracts has been investigated based on estimated ZI (Table 1) using aqueous and 6 different solvents. Overall, aqueous seaweed extracts were not active against all tested bacteria, whereas, seaweed extracts using the six solvents showed adverse antibacterial effect as expressed as ZI. For $C$. tomentosum, ZI value ranged between 3 (hexane against $K$. pneumoniae and V. cholerae) and $11 \mathrm{~mm}$ (methanol and acetone against $S$. typhimurium). whereas, this value ranged between $10 \mathrm{~mm}$ (hexane extracts against $S$. marcescens and $P$. vulgaris) and $17 \mathrm{~mm}$ (acetone against $S$. typhimurium) for $C$. mediterranea. As for $H$. musciformis, this value ranged between $5 \mathrm{~mm}$ with ethyl acetate against $A$. baumannii and $V$. cholerae, and $13 \mathrm{~mm}$ with chloroform against $E$. coli $\mathrm{O}: 157$. while, for $S$. vulgare, estimated ZI varied between $10 \mathrm{~mm}$ (ethyl acetate against $P$. vulgaris and $V$. cholerae) and $17 \mathrm{~mm}$ (methanol against $A$. baumannii). (Table 1). Seaweed crude extracts showed adverse effect against tested pathogens with different manner, according to the examined seaweed and solvent.

It is worth noting that the seaweed inhibitory effect against all tested gram negative bacteria was in the order of $S$. vulgare $(17 \mathrm{~mm})$ and $C$. mediterranea (17 $\mathrm{mm})>H$. musciformis $(13 \mathrm{~mm})>C$. tomentosum $(11$ $\mathrm{mm}$ ) (Table 1). In global, methanolic extracts of $C$. mediterranea and $S$. vulgare followed by ethanolic extracts showed relatively the strongest inhibitory effect against all tested microorganisms compared to acetonic one. This observation could be related to the synergetic effect of alkaloids and flavonoids components as bioactive compounds whereas, the same extract did not show similar effect in other examined algal species due to the absence of this synergetic effect.

Statistical variance analysis revealed that the effect of different extracts of seaweed species using different solvents was significantly different. In this respect, $H$. musciformis was more significant $(p<0.0005)$ vs $C$. mediterranea and $S$. vulgare for all microorganisms except $P$. vulgaris and $E$. coli $\mathrm{O}: 157$ isolates. Moreover, $C$. tomentosum was more significant $(p<0.0005)$ vs $C$. mediterranea, $S$. vulgare and $H$. musciformis for all microorganisms except $S$. marcescens, A bumanii and $P$. aeroginose for $H$. musciformis. In this respect, acetone extract of $C$. mediterranea was the best vs $S$. typhimurium and methanol extract of $S$. vulgare was the best vs A. bumanii (Table 1).

Previously, Kandhasamy and Arunachalam (2008) reported antibacterial activity of $H$. muciformis and $S$. myricocystum against $K$. pneumoniae, Enterobacter aerogenes, E. coli and $P$. aeruginosa, gram-negative bacteria. This study revealed that ZIs were found to be 13, 12, 0 and $12 \mathrm{~mm}$ with $H$. muciformis against $K$. pneumoniae, E. aerogenes, E. coli and P. aeruginosa, respectively, whereas, these were 13, 13, 0 and $12 \mathrm{~mm}$ with $S$. myricocystum against the same pathogens, respectively. Moreover, Chiheb et al. (2009) reported the biological activity of 32 macroalgae (13 Chlorophyta and 19 Phaeophyta) using methanol solvent, against 2 gram-negative bacteria (E. coli and $K$. pnomeuniae). This study showed that Cystoseira mediterranea among the Phaeophyceae displayed the highest ZI of $16 \mathrm{~mm}$ against E. coli whereas, Dictyota linearis (C. Agardh) Greville and Padina pavonica (Linnaeus) were potent against K. Pneumoniae with ZI of $15 \mathrm{~mm}$. Similarly, Ulva lactuca among the Chlorophyceae was the most active against $E$. coli with ZI of $16 \mathrm{~mm}$. Other investigations, however described the methalonic antibacterial activity of 20 species of marine benthic algae belonged to different algae members ( 9 Chlorophyceae, 3 Phaeophyceae and 8 Rhodophyceae), collected from the Mediterranean Moroccan coasts 
Table 1. Inhibitory effect of the four seaweed extracts using disc-diffusion method expressed as ZIs (mm)

\begin{tabular}{|c|c|c|c|c|c|c|c|}
\hline \multirow[b]{2}{*}{ Microorganisms } & \multicolumn{7}{|c|}{ Zone of inhibitions (ZIs) (mm) } \\
\hline & Methanol & Ethanol & Chloroform & Acetone & $\begin{array}{l}\text { Ethyl } \\
\text { acetate }\end{array}$ & Hexane & $\begin{array}{l}\text { Ciprofloxacin } \\
(\mathrm{mg} / \mathrm{L})\end{array}$ \\
\hline \multicolumn{8}{|l|}{ C. tomentosum } \\
\hline S. typhimurium & $11 \pm 0.25$ & $10 \pm 0.29$ & $9 \pm 0.18$ & $11 \pm 0.14$ & $10 \pm 0.26$ & $9 \pm 0.18$ & $27 \pm 0.18$ \\
\hline S. marcescens & $9 \pm 0.11$ & $10 \pm 0.09$ & $8 \pm 0.16$ & $7 \pm 0.2$ & $8 \pm 0.19$ & $7 \pm 0.17$ & $24 \pm 0.16$ \\
\hline E. coli $\mathrm{O}: 157$ & $9 \pm 0.15$ & $7 \pm 0.17$ & $9 \pm 0.19$ & $8 \pm 0.17$ & $6 \pm 0.09$ & $6 \pm 0.19$ & $23 \pm 0.35$ \\
\hline P. vulgaris & $9 \pm 0.15$ & $9 \pm 0.14$ & $6 \pm 0.08$ & $6 \pm 0.25$ & $7 \pm 0.09$ & $6 \pm 0.11$ & $24 \pm 0.4$ \\
\hline A. baumannii & $8 \pm 0.2$ & $8 \pm 0.27$ & $6 \pm 0.15$ & $5 \pm 0.19$ & $5 \pm 0.17$ & $4 \pm 0.12$ & $15 \pm 0.17$ \\
\hline B. melitensis & $7 \pm 0.16$ & $6 \pm 0.18$ & $5 \pm 0.06$ & $8 \pm 0.2$ & $8 \pm 0.22$ & $4 \pm 0.07$ & $20 \pm 0.32$ \\
\hline P. aeruginosa & $10 \pm 0.25$ & $9 \pm 0.11$ & $10 \pm 0.27$ & $8 \pm 0.09$ & $8 \pm 0.22$ & $6 \pm 0.19$ & $26 \pm 0.21$ \\
\hline K. pneumoniaee & $9 \pm 0.2$ & $9 \pm 0.07$ & $7 \pm 0.24$ & $6 \pm 0.15$ & $8 \pm 0.2$ & $3 \pm 0.06$ & $23 \pm 0.16$ \\
\hline S. flexneri & $9 \pm 0.11$ & $7 \pm 0.24$ & $7 \pm 0.15$ & $8 \pm 0.3$ & $9 \pm 0.25$ & $4 \pm 0.12$ & $31 \pm 0.2$ \\
\hline V. cholerae & $8 \pm 0.15$ & $6 \pm 0.09$ & $6 \pm 0.17$ & $5 \pm 0.18$ & $7 \pm 0.18$ & $3 \pm 0.07$ & $19 \pm 0.15$ \\
\hline \multicolumn{8}{|l|}{ C. mediterranea } \\
\hline S. typhimurium & $16 \pm 0.2^{2,5}$ & $14 \pm 0.17$ & $13 \pm 0.37$ & $17 \pm 0.28$ & $14 \pm 0.22$ & $11 \pm 0.4$ & $27 \pm 0.18$ \\
\hline S. marcescens & $14 \pm 0.2^{2,5}$ & $14 \pm 0.33$ & $12 \pm 0.29$ & $15 \pm 0.37$ & $13 \pm 0.27$ & $10 \pm 0.15$ & $24 \pm 0.16$ \\
\hline E. coli $\mathrm{O}: 157$ & $16 \pm 0.5^{2,5}$ & $13 \pm 0.18$ & $12 \pm 0.27$ & $16 \pm 0.45$ & $13 \pm 0.2$ & $11 \pm 0.09$ & $23 \pm 0.35$ \\
\hline P. vulgaris & $13 \pm 0.45^{5}$ & $14 \pm 0.19$ & $11 \pm 0.18$ & $15 \pm 0.2$ & $14 \pm 0.26$ & $10 \pm 0.11$ & $24 \pm 0.4$ \\
\hline A. baumannii & $13 \pm 0.21^{2,5}$ & $12 \pm 0.19$ & $13 \pm 0.33$ & $14 \pm 0.29$ & $13 \pm 0.2$ & $12 \pm 0.0$ & $15 \pm 0.17$ \\
\hline B. melitensis & $15 \pm 0.25^{2,5}$ & $13 \pm 0.35$ & $13 \pm 0.44$ & $15 \pm 0.5$ & $14 \pm 0.24$ & $11 \pm 0.27$ & $20 \pm 0.32$ \\
\hline P. aeruginosa & $13 \pm 0.29^{2,5}$ & $13 \pm 0.49$ & $11 \pm 0.37$ & $15 \pm 0.4$ & $13 \pm 0.24$ & $11 \pm 0.36$ & $26 \pm 0.21$ \\
\hline K. pneumoniaee & $14 \pm 0.33^{2,5}$ & $13 \pm 0.19$ & $12 \pm 0.27$ & $15 \pm 0.4$ & $13 \pm 0.25$ & $12 \pm 0.38$ & $23 \pm 0.16$ \\
\hline S. flexneri & $14 \pm 0.2^{2,5}$ & $12 \pm 0.29$ & $11 \pm 0.3$ & $14 \pm 0.26$ & $13 \pm 0.18$ & $13 \pm 0.55$ & $31 \pm 0.2$ \\
\hline V. cholerae & $15 \pm 0.13^{2,5}$ & $13 \pm 0.29$ & $12 \pm 0.39$ & $14 \pm 0.26$ & $13 \pm 0.24$ & $12 \pm 0.26$ & $19 \pm 0.15$ \\
\hline \multicolumn{8}{|l|}{ H. musciformis } \\
\hline S. typhimurium & $9 \pm 0.35^{6}$ & $6 \pm 0.2$ & $11 \pm 0.45$ & $10 \pm 0.31$ & $8 \pm 0.8$ & $9 \pm 0.5$ & $27 \pm 0.18$ \\
\hline S. marcescens & $9 \pm 0.33$ & $6 \pm 0.29$ & $7 \pm 0.3$ & $9 \pm 0.35$ & $9 \pm 0.4$ & $7 \pm 0.6$ & $24 \pm 0.16$ \\
\hline E. coli $\mathrm{O}: 157$ & $12 \pm 0.58^{6}$ & $11 \pm 0.45$ & $13 \pm 0.35$ & $11 \pm 0.27$ & $9 \pm 0.6$ & $12 \pm 0.33$ & $23 \pm 0.35$ \\
\hline P. vulgaris & $12 \pm 0.3^{4}$ & $7 \pm 0.19$ & $11 \pm 0.4$ & $9 \pm 0.22$ & $7 \pm 0.1$ & $10 \pm 0.5$ & $24 \pm 0.4$ \\
\hline A. baumannii & $9 \pm 0.19$ & $7 \pm 0.33$ & $9 \pm 0.35$ & $8 \pm 0.14$ & $5 \pm 0.15$ & $10 \pm 0.44$ & $15 \pm 0.17$ \\
\hline B. melitensis & $9 \pm 0.35^{6}$ & $6 \pm 0.22$ & $11 \pm 0.32$ & $10 \pm 0.43$ & $7 \pm 0.18$ & $10 \pm 0.4$ & $20 \pm 0.32$ \\
\hline P. aeruginosa & $9 \pm 0.4$ & $10 \pm 0.32$ & $11 \pm 0.54$ & $8 \pm 0.45$ & $7 \pm 0.26$ & $9 \pm 0.65$ & $26 \pm 0.21$ \\
\hline K. pneumoniaee & $11 \pm 0.35^{6}$ & $9 \pm 0.45$ & $12 \pm 0.40$ & $9 \pm 0.27$ & $10 \pm 0.55$ & $10 \pm 0.5$ & $23 \pm 0.16$ \\
\hline S. flexneri & $12 \pm 0.55^{6}$ & $10 \pm 0.29$ & $12 \pm 0.45$ & $9 \pm 0.3$ & $7 \pm 0.22$ & $11 \pm 0.48$ & $31 \pm 0.2$ \\
\hline V. cholerae & $10 \pm 0.19^{6}$ & $9 \pm 0.34$ & $11 \pm 0.27$ & $7 \pm 0.37$ & $5 \pm 0.25$ & $7 \pm 0.17$ & $19 \pm 0.15$ \\
\hline \multicolumn{8}{|l|}{ S. vulgare } \\
\hline S. typhimurium & $15 \pm 0.27^{1,5}$ & $15 \pm 0.32$ & $12 \pm 0.34$ & $13 \pm 0.36$ & $12 \pm 0.25$ & $12 \pm 0.34$ & $27 \pm 0.18$ \\
\hline S. marcescens & $14 \pm 0.4^{1,5}$ & $13 \pm 0.33$ & $13 \pm 0.52$ & $13 \pm 0.49$ & $12 \pm 0.38$ & $11 \pm 0.22$ & $24 \pm 0.16$ \\
\hline E. coli $\mathrm{O}: 157$ & $15 \pm 0.16^{3,5}$ & $15 \pm 0.4$ & $13 \pm 0.28$ & $12 \pm 0.35$ & $12 \pm 0.5$ & $11 \pm 0.45$ & $23 \pm 0.35$ \\
\hline P. vulgaris & $16 \pm 0.55^{1,5}$ & $14 \pm 0.42$ & $12 \pm 0.22$ & $13 \pm 0.35$ & $10 \pm 0.29$ & $11 \pm 0.34$ & $24 \pm 0.4$ \\
\hline A. baumannii & $17 \pm 0.55^{1,5}$ & $15 \pm 0.42$ & $12 \pm 0.33$ & $13 \pm 0.28$ & $13 \pm 0.45$ & $12 \pm 0.45$ & $15 \pm 0.17$ \\
\hline B. melitensis & $16 \pm 0.35^{1,5}$ & $14 \pm 0.3$ & $11 \pm 0.29$ & $13 \pm 0.4$ & $11 \pm 0.42$ & $12 \pm 0.55$ & $20 \pm 0.32$ \\
\hline P. aeruginosa & $15 \pm 0.44^{1,5}$ & $14 \pm 0.36$ & $12 \pm 0.46$ & $14 \pm 0.44$ & $11 \pm 0.24$ & $11 \pm 0.4$ & $26 \pm 0.21$ \\
\hline K. pneumoniaee & $16 \pm 0.45^{1,5}$ & $15 \pm 0.54$ & $13 \pm 0.27$ & $13 \pm 0.44$ & $12 \pm 0.3$ & $11 \pm 0.35$ & $23 \pm 0.16$ \\
\hline S. flexneri & $15 \pm 0.53^{1,5}$ & $15 \pm 0.5$ & $11 \pm 0.44$ & $13 \pm 0.29$ & $11 \pm 0.33$ & $12 \pm 0.22$ & $31 \pm 0.2$ \\
\hline V. cholerae & $13 \pm 0.26^{1,5}$ & $14 \pm 0.44$ & $11 \pm 0.38$ & $13 \pm 0.34$ & $10 \pm 0.23$ & $12 \pm 0.37$ & $19 \pm 0.15$ \\
\hline
\end{tabular}

Comparing the effect of the same solvent by using extracts from different seaweed, methanol is the best solvent; - Using H. musciformis; $1 \mathrm{p}<0.0005$ vs $S$. vulgare for all microorganisms except $E$. coli $\mathrm{O}: 157 ; 2 \mathrm{p}<0.0005$ vs $C$. mediterranea for all microorganisms except $P$. vulgaris; - Using C. mediterranea;3p $<0.05$ vs $S$. vulgare for E. coli $0: 157 ; 4 \mathrm{p}<0.05$ vs $H$. musciformis for P. vulgaris; - Using C. tomentosum; $5 \mathrm{p}<0.0005$ vs $S$. vulgare and $C$. mediterranea for all microorganisms; $6 \mathrm{p}<0.0005$ vs $H$. musciformis for all microorganisms except $S$. marcescens, A. baumannii and $P$. aeruginosa microorganisms. 
(Zbakh et al., 2012). This investigation revealed that the Rhodophyceae among the 3 examined algae groups were the most potent by showing the highest ZIs varied between 20-24 mm. Rhimou et al. (2010) also reviewed inhibitory effects of 26 red seaweed collected from Morocco using methanolic crude extracts against two gram negative bacterial isolates. This study showed that out of the 26 seaweeds, H. musciformis extracts displayed the highest inhibition zone of $20.67 \mathrm{~mm}$ and $19.00 \mathrm{~mm}$ against $E$. coli and $K$. pneumoniae, respectively.

Jeyaseelan et al. (2012) studied ethanol extracts of 5 algal (S. polycystum, S. tenerrimum, Turbinaria ornata, Gracilaria crassa and Codium fragile) species collected from different coastal regions of Sri Lanka; against $E$. coli as a gram-negative bacteria and the highest activity was recorded with sequentially extracted ethanol extract of $C$. fragile $(12.2 \mathrm{~mm})$. Other investigation however, showed the utility of $H$. musciformis as a promising source for antimicrobial effect against E. coli, S. typhi and $P$. aeruginosa (Shareef et al., 2012). Similarly, Ramalingami and Amutha (2013) investigated the antibacterial activity of 4 algae species collected from Thondi Coast, Tamilnadu - India against 5 gram-negative bacteria using acetone, methanol, chloroform, diethyl ether, ethyl acetate, hexane and water. This study revealed that the ZIs were found to be $<8 \mathrm{~mm}$ for all examined algal extracts. Moreover the chloroform extract displayed the highest activity and Acanthophora spicifera extracts were the most active whereas, $S$. wightii were the lowest ones. Elnabris et al. (2013) reported the inhibitory effect of 4 methanolic extracts of algae species Enteromorpha compressa and Ulva lactuca (Chlorophyta); Jania rubens (Rhodophyta) and P. pavonica (Phaeophyta) collected from Palestine for their antibacterial activity against 4 gram-negative bacterial isolates ( $P$. aeruginosa, E. coli, $K$. pneumoniae and $P$. vulgaris). This study showed that the highest ZI was obtained with green $U$. lactuca algae with 9.8 and $5.8 \mathrm{~mm}$ against $K$. pneumoniae and $P$. vulgaris isolates, respectively. However, J. rubens (red) and $P$. pavonica (brown) displayed the lowest activity. Chandrasekaran et al. (2014) studied $S$. wightii antibacterial activity against 8 gram-negative bacterial isolates. This investigation showed that ZIs varied between $10.1 \mathrm{~mm}$ (methanol) - $12.6 \mathrm{~mm}$ (ethyl acetate) against $E$. coli; between $10.5 \mathrm{~mm}$ (acetone and methanol) $-12.8 \mathrm{~mm}$ (ethyl acetate) against $K$. pneumoniae; between $9.8 \mathrm{~mm}$ (hexane) - $12.8 \mathrm{~mm}$ (ethyl acetate) against $P$. vulgaris, whereas, it ranged between 10.1 $\mathrm{mm}$ (hexane) - $13.1 \mathrm{~mm}$ (ethyl acetate) against $P$. aeruginosa; between $10.6 \mathrm{~mm}$ (acetone and methanol) - $13.3 \mathrm{~mm}$ (ethyl acetate) against $S$. typhimurium; and between 10.8 (methanol) - $13.1 \mathrm{~mm}$ (ethyl acetate) against $S$. flexneri. Kavita et al. (2014) also showed that the methanolic extract of Laurencia papillosa (Rhodophyceae) extract among 11 algae species exhibited the strongest inhibitory effect with ZIS of 12.33 and $11.66 \mathrm{~mm}$ against E.coli and P. aeruginosa bacteria, respectively.

Recently, Kausalya and Rao (2015) investigated antimicrobial activity of $S$. polycystum and S. tenerrimum collected from India against 6 gram-negative bacteria using chloroform, ethanol, methanol and water solvents. This study revealed that the highest ZI was observed in the case of methanol against $P$. vulgaris and $K$. pneumoniae (18 mm). Sushanth and Rajashekhar (2015) investigated the antimicrobial activity of ethanol, methanol and hexane extracts for Chaetoceros calcitrans, Skeletonema costatum, Chroococcuc turgidus and Nannochloropsis oceanica microalgae collected from Arabian Sea of Karnataka Coast, against 4 gram-negative bacterial strains. This investigation revealed that, ZI values ranged between $6.1 \mathrm{~mm}$ (with ethanol extract of $S$. costatum against $K$. pneumoniae) and $21.4 \mathrm{~mm}$ (with hexane extract of $C$. turgidus against $E$. coli). Karthick et al. (2015) investigated the antibacterial activity of methanolic extracts from 5 algae (2 green 2 red and 1 brown species collected from South Andaman, India) against 4 gram-negative (E.coli, S. typhi, P. aeruginosa and $K$. pneumoniae) bacterial isolates, the highest ZI was recorded with methanolic extracts of Dictyosphaeria cavernosa $(16 \mathrm{~mm})$ against $K$. pneumoniae and for Galaxura marginata $(16 \mathrm{~mm})$ against E.coli, whereas, Acetabularia calyculus extract exhibited the lowest ZI value $(11 \mathrm{~mm})$ against E.coli; with no inhibitory activity against the 3 other tested isolates. Moreover, the same study showed that Corallina sp. extract was not active against all examined pathogens. More recently, Boujaber et al. (2016) reported Gelidium sesquipedale (red) and Laminaria ochroleuca (brown) collected from the Mediterranean Moroccan coasts inhibitory effects against two gram-negative bacterial isolates $(E$. coli and Pseudomonas sp.) using hexane, dichloromethane, dichloromethane/methanol (50:50), methanol and water as solvents. This study demonstrated that the dichloromethane/methanol showed the strongest antibacterial activity with ZI of $14 \mathrm{~mm}$ for $G$. sesquipedale, whereas, it was recorded to be 13 and $16 \mathrm{~mm}$ in the case of L. ochroleuca against E. coli and 
Pseudomonas sp., respectively while aqueous, hexane and dichloromethane extracts of both algae showed no activity against all examined bacterial pathogens.

Recently Alves et al. (2016) reviewed antimicrobial activity of five seaweeds (2 Chlorophyta, 1 Rhodophyta and 2 Phaeophyta) collected from Brazil, using hexane, chloroform, ethyl acetate and methanol solvents against E. coli and K. pneumoniae isolates and revealed that methanolic extract of $S$. polyceratium (Phaeophyta) displayed ZIs of 15 and $8.67 \mathrm{~mm}$ against $E$. coli and $K$. pneumoniae isolates, respectively.

Minimum inhibitory concentration (MIC) and minimal bactericidal concentration (MBC) assay. To investigate seaweed inhibition activity, $\mathrm{MIC}_{50}$ values were also estimated (Table 2). In this regards, for $C$. tomentosum, this value varied between $3.3 \mathrm{mg} / \mathrm{mL}$ (methanol against $E$. coli O:157; acetone against $A$. baumanni, P. aeruginosa and $S$. flexneri ) and $>10$ $\mathrm{mg} / \mathrm{mL}$ with hexane against all isolates except $S$. typhimurium $(10.0 \mathrm{mg} / \mathrm{mL})$. As for C. mediterranea, this value varied between $1.0 \mathrm{mg} / \mathrm{mL}$ with methanol against $S$. marcescens, and E. coli O:157; and 10.0 $\mathrm{mg} / \mathrm{mL}$ with hexane against $P$. vulgaris, B. melitensis, $P$. aeruginosa and $K$. pneumoniae isolates whereas, in the case of $H$. musciformis this value ranged between $13.3 \mathrm{mg} / \mathrm{mL}$ (methanol against $S$. typhimurium, $S$. marcescens, A. baumanni, $P$. aeruginosa and $K$. pneumoniae) and $80.0 \mathrm{mg} / \mathrm{mL}$ with hexane against $S$. flexneri. while, for $S$. vulgare, this value varied between $0.08 \mathrm{mg} / \mathrm{mL}$ (hexane against $E$. coli $\mathrm{O}: 157$ and methanol against $S$. flexneri) and $0.32 \mathrm{mg} / \mathrm{mL}$ with ethyl acetate against $P$. vulgaris, B. melitensis and $K$. pneumoniae isolates (Table 2).

Statistical variance analysis revealed that comparing the effect of the same solvent by using extracts from different seaweeds, methanolic extracts were the best. This effect was significant $(p=0.05)$ vs $C$. mediterranea and C. tomentosum for S. flexneri and also $(p=0.0005)$ vs all other algae for all organisms except $S$. flexneri (Table 2).

Moreover, seaweed antibacterial potency to kill tested isolates has been evaluated by determination of MBC values (Table 3). Overall, MBC values followed similar tendency of $\mathrm{MIC}_{50}$. In this respect, the lowest MBC values $(1.00 \mathrm{mg} / \mathrm{mL})$ were recorded for $S$. vulgare with methanol against $S$. typhimurium, $S$. marcescens, $E$. coli $\mathrm{O}: 157$ and $B$. melitensis isolates and ethanol against S. mancesces and E.coli 0.157.(Table 3).
Variance analysis in comparing the effect of the same solvent by using extracts from different seaweed showed that methanolic extracts of $S$. vulgare were the most potent. This inhibitory effect was significant $(p=0.005)$ vs $C$. tomentosum against $K$. pneumoniae (Table 3 ). It is worth noting that the highest relative phenolic content observed in $S$. vulgare seaweed as well as the presence of the other bioactive components lead to their better and potent effect against tested bacterial isolates.

In this regards, methanol, ethanol and hexane extracts of $S$. vulgare showed the most potent activity against examined pathogens by showing lowest $\mathrm{MIC}_{50} / \mathrm{MBC}$ values of $0.08 / 1.00 \mathrm{mg} / \mathrm{mL}$ against $E$. coli $\mathrm{O}: 157$ isolate as mentioned in Tables 2-3. The observed highest antimicrobial activity of $S$. vulgare extracts could be related to their bioactive compounds such as flavonoids, terpenoids, tannins, carbohydrates and highly phenolic compounds present in methanolic extracts; whereas, terpenoids, phenols and highly saponins compounds were found in hexane extracts. These compounds constitute an important class as secondary metabolites reported to display strong antimicrobial activity.

More recently, Perez et al. (2016) reviewed the antimicrobial potential effect of seaweed related to their different bioactive constituents such as polysaccharides, fatty acids, phlorotannins, pigments, lectins, alkaloids, terpenoids and halogenated compounds. Tajbakhsh et al. (2011) reported the antibacterial activity of $S$. oligocystum (collected from south west of Iran) against 2 gram-negative bacterial pathogens ( $P$. aeruginosa and E. coli). This study showed that hot water displayed an inhibitory activity with MIC value recorded to be 9.556 $\mathrm{mg} / \mathrm{mL}$ against $P$. aeruginos $a$ isolate. Whereas, Inhibitory effect of S. polycystum and P. australis (brown) seaweed against 3 gram- negative bacteria isolates was reported using methanol, dichloromethane and $n$-hexane solvents, showed that $S$. polycystum seaweed was more potent as compared to $P$. australis. In this regards, the lowest MIC of S. polycystum extracts against $E$. coli were $0.521 \mathrm{mg} / \mathrm{mL}$ (methanol) and $0.417 \mathrm{mg} / \mathrm{mL}$ (n-hexane) and were $0.104 \mathrm{mg} / \mathrm{mL}$ ( $n$-Hexane) and $0.208 \mathrm{mg} / \mathrm{mL}$ (methanol and dichloromethane), respectively against P. aeruginosa. As for bactericidal effect (MBC), the two examined seaweed extracts were non active against the tested isolates regardless of examined solvent (ChiaoWei et al., 2011)

Moreover, Chandrasekaran et al. (2014) also reported inhibitory activity of $S$. wightii expressed as MIC and $\mathrm{MBC}$ values. In this respect, MIC values ranged between 
Table 2. Minimum inhibition concentrations $\left(\mathrm{MIC}_{50}\right)$ values of the four seaweed extracts against the tested isolates

\begin{tabular}{|c|c|c|c|c|c|c|c|}
\hline \multirow[b]{2}{*}{ Microorganisms } & \multicolumn{7}{|c|}{ Minimum inhibitory concentration $\left(\mathrm{MIC}_{50}\right)(\mathrm{mg} / \mathrm{mL})$} \\
\hline & Methanol & Ethanol & Chloroform & Acetone & $\begin{array}{l}\text { Ethyl } \\
\text { acetate }\end{array}$ & Hexane & $\begin{array}{l}\text { Ciprofloxacin } \\
(\mathrm{mg} / \mathrm{L})\end{array}$ \\
\hline \multicolumn{8}{|l|}{ C. tomentosum } \\
\hline S. typhimurium & $6.7 \pm 2.9 * *$ & $6.7 \pm 2.9$ & $8.3 \pm 2.9$ & $6.7 \pm 2.9$ & $6.7 \pm 2.9$ & $10.0 \pm 0.0$ & $0.25 \pm 0.13$ \\
\hline S. marcescens & $4.2 \pm 1.4 * *$ & $5.8 \pm 3.8$ & $5.8 \pm 3.8$ & $5.0 \pm 0.0$ & $4.2 \pm 1.4$ & $>10.0 \pm 0.0$ & $0.5 \pm 0.11$ \\
\hline E. coli $\mathrm{O}: 157$ & $3.3 \pm 1.4 * *$ & $5.8 \pm 3.8$ & $8.3 \pm 2.9$ & $5.8 \pm 3.8$ & $4.2 \pm 1.4$ & $>10.0 \pm 0.0$ & $4.0 \pm 0.5$ \\
\hline P. vulgaris & $5.0 \pm 0.0 * *$ & $5.8 \pm 3.8$ & $6.7 \pm 2.9$ & $4.2 \pm 1.4$ & $5.8 \pm 3.8$ & $>10.0 \pm 0.0$ & $1.0 \pm 0.13$ \\
\hline A. baumannii & $4.2 \pm 1.4 * *$ & $4.2 \pm 1.4$ & $5.8 \pm 3.8$ & $3.3 \pm 1.4$ & $5.0 \pm 0.0$ & $>10.0 \pm 0.0$ & $64 \pm 0.26$ \\
\hline B. melitensis & $5.0 \pm 0.0 * *$ & $6.7 \pm 2.9$ & $8.3 \pm 2.9$ & $5.0 \pm 0.0$ & $5.8 \pm 3.8$ & $>10.0 \pm 0.0$ & $0.5 \pm 0.09$ \\
\hline$P$. aeruginosa & $4.2 \pm 1.4 * *$ & $5.8 \pm 3.8$ & $6.7 \pm 2.9$ & $3.3 \pm 1.4$ & $4.2 \pm 1.4$ & $>10.0 \pm 0.0$ & $1.0 \pm 0.2$ \\
\hline K. pneumoniaee & $5.8 \pm 3.8^{* *}$ & $8.3 \pm 2.9$ & $6.7 \pm 2.9$ & $5.8 \pm 3.8$ & $6.7 \pm 2.9$ & $>10.0 \pm 0.0$ & $6.0 \pm 0.15$ \\
\hline S. flexneri & $4.2 \pm 1.4^{*}$ & $4.2 \pm 1.4$ & $5.0 \pm 0.0$ & $3.3 \pm 1.4$ & $4.2 \pm 1.4$ & $>10.0 \pm 0.0$ & $0.38 \pm 0.11$ \\
\hline V. cholerae & $5.0 \pm 0.0 * *$ & $6.7 \pm 2.9$ & $8.3 \pm 2.9$ & $5.8 \pm 3.8$ & $5.8 \pm 3.8$ & $>10.0 \pm 0.0$ & $0.75 \pm 0.07$ \\
\hline \multicolumn{8}{|l|}{ C. mediterranea } \\
\hline S. typhimurium & $1.3 \pm 0.0 * *$ & $1.7 \pm 0.7$ & $2.1 \pm 0.7$ & $1.7 \pm 0.7$ & $2.1 \pm 0.7$ & $6.7 \pm 2.9$ & $0.25 \pm 0.13$ \\
\hline S. marcescens & $1.0 \pm 0.4 * *$ & $1.7 \pm 0.7$ & $3.3 \pm 1.4$ & $1.3 \pm 0.0$ & $2.1 \pm 0.7$ & $6.7 \pm 2.9$ & $0.5 \pm 0.11$ \\
\hline E. coli $\mathrm{O}: 157$ & $1.0 \pm 0.4 * *$ & $1.7 \pm 0.7$ & $2.1 \pm 0.7$ & $1.3 \pm 0.0$ & $1.7 \pm 0.7$ & $8.3 \pm 2.9$ & $4.0 \pm 0.5$ \\
\hline P. vulgaris & $1.7 \pm 0.7^{* *}$ & $2.1 \pm 0.7$ & $2.9 \pm 1.9$ & $1.7 \pm 0.7$ & $2.1 \pm 0.7$ & $10.0 \pm 0.0$ & $1.0 \pm 0.13$ \\
\hline A. baumannii & $4.2 \pm 1.4 * *$ & $4.2 \pm 1.4$ & $6.7 \pm 2.9$ & $8.3 \pm 2.9$ & $3.3 \pm 1.4$ & ND & $64 \pm 0.26$ \\
\hline B. melitensis & $1.4 \pm 0.4 * *$ & $1.4 \pm 0.7$ & $2.9 \pm 0.7$ & $2.9 \pm 0.7$ & $1.4 \pm 0.7$ & $10.0 \pm 0.0$ & $0.5 \pm 0.09$ \\
\hline P. aeruginosa & $2.1 \pm 0.7 * *$ & $2.5 \pm 0.0$ & $2.9 \pm 1.9$ & $1.7 \pm 0.7$ & $2.5 \pm 0.0$ & $10.0 \pm 0.0$ & $1.0 \pm 0.2$ \\
\hline K. pneumoniaee & $2.1 \pm 0.7 * *$ & $3.3 \pm 1.4$ & $3.3 \pm 1.4$ & $2.1 \pm 0.7$ & $3.3 \pm 1.4$ & $10.0 \pm 0.0$ & $6.0 \pm 0.15$ \\
\hline S. flexneri & $1.7 \pm 0.7^{*}$ & $2.1 \pm 0.7$ & $3.3 \pm 1.4$ & $1.3 \pm 2.2$ & $3.3 \pm 1.9$ & ND & $0.38 \pm 0.11$ \\
\hline V. cholerae & $2.1 \pm 0.7^{* *}$ & $2.1 \pm 0.7$ & $3.3 \pm 1.4$ & $2.5 \pm 2.2$ & $2.9 \pm 1.9$ & ND & $0.75 \pm 0.07$ \\
\hline \multicolumn{8}{|l|}{ H. musciformis } \\
\hline S. typhimurium & $13.3 \pm 5.8^{* *}$ & $20.0 \pm 0.0$ & $23.3 \pm 15.3$ & $26.7 \pm 11.5$ & $33.3 \pm 11.5$ & $40.0 \pm 0.0$ & $0.25 \pm 0.13$ \\
\hline S. marcescens & $13.3 \pm 5.8^{* *}$ & $26.6 \pm 11.5$ & $30.0 \pm 17.3$ & $26.7 \pm 11.5$ & $33.3 \pm 11.5$ & $26.7 \pm 11.5$ & $0.5 \pm 0.11$ \\
\hline E. coli $\mathrm{O}: 157$ & $16.7 \pm 5.8^{* *}$ & $16.7 \pm 5.8$ & $23.3 \pm 15.3$ & $23.3 \pm 15.3$ & $33.3 \pm 11.5$ & $33.3 \pm 11.5$ & $4.0 \pm 0.5$ \\
\hline P. vulgaris & $16.7 \pm 5.8^{* *}$ & $23.3 \pm 15.3$ & $26.7 \pm 11.5$ & $40.0 \pm 0.0$ & $46.7 \pm 30.5$ & $53.3 \pm 23.1$ & $1.0 \pm 0.13$ \\
\hline A. baumannii & $13.3 \pm 5.8^{* *}$ & $23.3 \pm 15.3$ & $33.3 \pm 11.5$ & $33.3 \pm 11.5$ & $53.3 \pm 23.1$ & $53.3 \pm 23.1$ & $64 \pm 0.26$ \\
\hline B. melitensis & $20.0 \pm 0.0 * *$ & $33.3 \pm 11.5$ & $23.3 \pm 15.3$ & $40.0 \pm 0.0$ & $46.7 \pm 30.6$ & $66.7 \pm 23.1$ & $0.5 \pm 0.09$ \\
\hline P. aeruginosa & $13.3 \pm 5.8^{* *}$ & $23.3 \pm 15.3$ & $26.7 \pm 11.5$ & $33.3 \pm 11.5$ & $33.3 \pm 11.5$ & $53.3 \pm 23.1$ & $1.0 \pm 0.2$ \\
\hline K. pneumoniaee & $13.3 \pm 5.9 * *$ & $26.7 \pm 11.5$ & $26.7 \pm 11.5$ & $46.7 \pm 30.6$ & $46.7 \pm 30.6$ & $53.3 \pm 23.1$ & $6.0 \pm 0.15$ \\
\hline S. flexneri & $23.3 \pm 15.3$ & $30.0 \pm 17.3$ & $33.3 \pm 11.5$ & $40.0 \pm 0.0$ & $66.7 \pm 23.1$ & $80.0 \pm 0.0$ & $0.38 \pm 0.11$ \\
\hline V. cholerae & $16.7 \pm 5.8^{* *}$ & $26.7 \pm 11.5$ & $30.0 \pm 17.3$ & $60.0 \pm 34.6$ & $53.3 \pm 23.1$ & $66.7 \pm 23.1$ & $0.75 \pm 0.07$ \\
\hline \multicolumn{8}{|l|}{ S. vulgare } \\
\hline S. typhimurium & $0.13 \pm 0.1$ & $0.21 \pm 0.1$ & $0.11 \pm 0.0$ & $0.13 \pm 0.1$ & $0.27 \pm 0.1$ & $0.11 \pm 0.1$ & $0.25 \pm 0.13$ \\
\hline S. marcescens & $0.16 \pm 0.1$ & $0.21 \pm 0.1$ & $0.13 \pm 0.1$ & $0.19 \pm 0.1$ & $0.21 \pm 0.1$ & $0.13 \pm 0.1$ & $0.5 \pm 0.11$ \\
\hline E. coli $\mathrm{O}: 157$ & $0.11 \pm 0.1$ & $0.16 \pm 0.1$ & $0.11 \pm 0.0$ & $0.13 \pm 0.0$ & $0.27 \pm 0.0$ & $0.08 \pm 0.1$ & $4.0 \pm 0.5$ \\
\hline P. vulgaris & $0.13 \pm 0.1$ & $0.19 \pm 0.0$ & $0.13 \pm 0.1$ & $0.19 \pm 0.1$ & $0.32 \pm 0.1$ & $0.27 \pm 0.1$ & $1.0 \pm 0.13$ \\
\hline A. baumannii & $0.11 \pm 0.1$ & $0.21 \pm 0.1$ & $0.11 \pm 0.1$ & $0.19 \pm 0.1$ & $0.27 \pm 0.1$ & $0.13 \pm 0.1$ & $64 \pm 0.26$ \\
\hline B. melitensis & $0.11 \pm 0.1$ & $0.31 \pm 0.1$ & $0.13 \pm 0.1$ & $0.13 \pm 0.1$ & $0.32 \pm 0.1$ & $0.11 \pm 0.2$ & $0.5 \pm 0.09$ \\
\hline P. aeruginosa & $0.13 \pm 0.2$ & $0.19 \pm 0.0$ & $0.16 \pm 0.1$ & $0.21 \pm 0.1$ & $0.27 \pm 0.1$ & $0.27 \pm 0.1$ & $1.0 \pm 0.2$ \\
\hline K. pneumoniaee & $0.16 \pm 0.1$ & $0.21 \pm 0.1$ & $0.21 \pm 0.1$ & $0.21 \pm 0.1$ & $0.32 \pm 0.1$ & $0.11 \pm 0.1$ & $6.0 \pm 0.15$ \\
\hline S. flexneri & $0.08 \pm 0.0$ & $0.13 \pm 0.1$ & $0.11 \pm 0.1$ & $0.16 \pm 0.1$ & $0.27 \pm 0.1$ & $0.11 \pm 0.1$ & $0.38 \pm 0.11$ \\
\hline V. cholerae & $0.11 \pm 0.1$ & $0.21 \pm 0.1$ & $0.13 \pm 0.1$ & $0.21 \pm 0.1$ & $0.27 \pm 0.1$ & $0.11 \pm 0.0$ & $0.75 \pm 0.07$ \\
\hline
\end{tabular}

ND: not determined; Comparing the effect of the same solvent by using extracts from different seaweed, methanol is the best solvent; - using $S$. vulgare; ${ }^{*} \mathrm{p}<0.05$ vs $C$. mediterranea and $C$. tomentosum for $S$. flexneri; ${ }^{*} \mathrm{p}<0.0005$ vs all other seaweed for all microorganisms except $S$. flexneri.

$0.250 \mathrm{mg} / \mathrm{mL}$ (ethyl acetate) and $0.5 \mathrm{mg} / \mathrm{mL}$ (hexane, chloroform, acetone and methanol). Whereas, for MBC these varied between $0.5 \mathrm{mg} / \mathrm{mL}$ (ethyl acetate) and
$1 \mathrm{mg} / \mathrm{mL}$ (hexane, chloroform, acetone and methanol). An other study revealed that the methanolic extract of L. papillosa (Rhodophyceae) among 11 algae species 
Table 3. Minimum bactericidal concentrations (MBC) values of the four seaweed extracts against the tested isolates

\begin{tabular}{|c|c|c|c|c|c|c|c|}
\hline \multirow[b]{2}{*}{ Microorganisms } & \multicolumn{7}{|c|}{ Minimum bactericidal concentration $(\mathrm{MBC})(\mathrm{mg} / \mathrm{mL})$} \\
\hline & Methanol & Ethanol & Chloroform & Acetone & $\begin{array}{l}\text { Ethyl } \\
\text { acetate }\end{array}$ & Hexane & $\begin{array}{l}\text { Ciprofloxacin } \\
(\mathrm{mg} / \mathrm{L})\end{array}$ \\
\hline \multicolumn{8}{|l|}{ C. tomentosum } \\
\hline S. typhimurium & $8.3 \pm 2.9$ & $10.0 \pm 0.0$ & $>10.0 \pm 0.0$ & $>10.0 \pm 0.0$ & $>10.0 \pm 0.0$ & $>10.0 \pm 0.0$ & $0.5 \pm 0.18$ \\
\hline S. marcescens & $6.7 \pm 2.9$ & $8.3 \pm 2.9$ & $>10.0 \pm 0.0$ & $8.3 \pm 2.9$ & $>10.0 \pm 0.0$ & $>10.0 \pm 0.0$ & $1.0 \pm 0.15$ \\
\hline E. coli $\mathrm{O}: 157$ & $8.3 \pm 2.9 \mathrm{e}$ & $>10.0 \pm 0.0$ & $>10.0 \pm 0.0$ & $8.3 \pm 2.9$ & $>10.0 \pm 0.0$ & $>10.0 \pm 0.0$ & $8.0 \pm 0.4$ \\
\hline P. vulgaris & $8.3 \pm 2.9 \mathrm{e}$ & $>10.0 \pm 0.0$ & $>10.0 \pm 0.0$ & $>10.0 \pm 0.0$ & $>10.0 \pm 0.0$ & $>10.0 \pm 0.0$ & $1.75 \pm 0.32$ \\
\hline A. baumannii & $8.3 \pm 2.9$ & $>10.0 \pm 0.0$ & $>10.0 \pm 0.0$ & $>10.0 \pm 0.0$ & $>10.0 \pm 0.0$ & $>10.0 \pm 0.0$ & $128 \pm 0.48$ \\
\hline B. melitensis & $8.3 \pm 2.9 \mathrm{e}$ & $>10.0 \pm 0.0$ & $>10.0 \pm 0.0$ & $>10.0 \pm 0.0$ & $>10.0 \pm 0.0$ & $>10.0 \pm 0.0$ & $1.0 \pm 0.24$ \\
\hline P. aeruginosa & $8.3 \pm 2.9$ & $>10.0 \pm 0.0$ & $>10.0 \pm 0.0$ & $>10.0 \pm 0.0$ & $>10.0 \pm 0.0$ & $>10.0 \pm 0.0$ & $2.0 \pm 0.15$ \\
\hline K. pneumoniaee & $>10.0 \pm 0.0 \mathrm{a}$ & $>10.0 \pm 0.0$ & $>10.0 \pm 0.0$ & $>10.0 \pm 0.0$ & $>10.0 \pm 0.0$ & $>10.0 \pm 0.0$ & $12.0 \pm 0.19$ \\
\hline S. flexneri & $8.3 \pm 2.9 f$ & $>10.0 \pm 0.0$ & $>10.0 \pm 0.0$ & $>10.0 \pm 0.0$ & $>10.0 \pm 0.0$ & $>10.0 \pm 0.0$ & $0.75 \pm 0.09$ \\
\hline V. cholerae & $10.0 \pm 0.0$ & $>10.0 \pm 0.0$ & $>10.0 \pm 0.0$ & $>10.0 \pm 0.0$ & $>10.0 \pm 0.0$ & $>10.0 \pm 0.0$ & $1.5 \pm 0.14$ \\
\hline \multicolumn{8}{|l|}{ C. mediterranea } \\
\hline S. typhimurium & $2.1 \pm 0.7 \mathrm{~d}$ & $2.9 \pm 1.9$ & $3.3 \pm 1.4$ & $2.1 \pm 0.7$ & $3.3 \pm 1.4$ & $8.3 \pm 2.9$ & $0.5 \pm 0.18$ \\
\hline S. marcescens & $1.7 \pm 0.7 \mathrm{~d}$ & $2.9 \pm 1.9$ & $4.2 \pm 1.4$ & $2.1 \pm 0.7$ & $3.3 \pm 1.4$ & $8.3 \pm 2.9$ & $1.0 \pm 0.15$ \\
\hline E. coli $\mathrm{O}: 157$ & $1.7 \pm 0.7 \mathrm{~d}$ & $1.7 \pm 0.7$ & $2.1 \pm 0.7$ & $2.1 \pm 0.7$ & $2.9 \pm 1.9$ & $8.3 \pm 2.9$ & $8.0 \pm 0.4$ \\
\hline P. vulgaris & $2.1 \pm 0.7 \mathrm{~d}$ & $3.3 \pm 1.4$ & $4.2 \pm 1.4$ & $2.5 \pm 0.0$ & $3.3 \pm 1.4$ & $10.0 \pm 0.0$ & $1.75 \pm 0.32$ \\
\hline A. baumannii & $5.0 \pm 0.0 \mathrm{c}$ & $5.0 \pm 0.0$ & $8.3 \pm 2.9$ & $10.0 \pm 0.0$ & $6.7 \pm 2.9$ & $>10.0 \pm 0.0$ & $128 \pm 0.48$ \\
\hline B. melitensis & $2.1 \pm 0.7 \mathrm{~d}$ & $2.5 \pm 0.0$ & $3.3 \pm 1.4$ & $3.3 \pm 1.4$ & $3.3 \pm 1.4$ & $10.0 \pm 0.0$ & $1.0 \pm 0.24$ \\
\hline P. aeruginosa & $3.3 \pm 1.4 \mathrm{~d}$ & $4.2 \pm 1.4$ & $4.2 \pm 1.4$ & $2.5 \pm 0.0$ & $4.2 \pm 1.4$ & $>10.0 \pm 0.0$ & $2.0 \pm 0.15$ \\
\hline K. pneumoniaee & $3.3 \pm 1.4 \mathrm{~d}$ & $4.2 \pm 1.4$ & $4.2 \pm 1.4$ & $3.3 \pm 1.4$ & $5.0 \pm 0.0$ & $>10.0 \pm 0.0$ & $12.0 \pm 0.19$ \\
\hline S. flexneri & $2.5 \pm 0.0 \mathrm{~d}$ & $3.3 \pm 1.4$ & $4.2 \pm 1.4$ & $2.1 \pm 0.7$ & $4.2 \pm 1.4$ & $>10.0 \pm 0.0$ & $0.75 \pm 0.09$ \\
\hline V. cholerae & $3.3 \pm 1.4 \mathrm{~d}$ & $3.3 \pm 1.4$ & $4.2 \pm 1.4$ & $3.3 \pm 1.4$ & $4.2 \pm 1.4$ & $>10.0 \pm 0.0$ & $1.5 \pm 0.14$ \\
\hline \multicolumn{8}{|l|}{ H. musciformis } \\
\hline S. typhimurium & $16.7 \pm 5.8$ & $>20.0 \pm 0.0$ & $>20.0 \pm 0.0$ & $>20.0 \pm 0.0$ & $>20.0 \pm 0.0$ & $>20.0 \pm 0.0$ & $0.5 \pm 0.18$ \\
\hline S. marcescens & $16.7 \pm 5.8$ & $20.0 \pm 0.0$ & $>20.0 \pm 0.0$ & $>20.0 \pm 0.0$ & $>20.0 \pm 0.0$ & $>20.0 \pm 0.0$ & $1.0 \pm 0.15$ \\
\hline E. coli $\mathrm{O}: 157$ & $20.0 \pm 0.0$ & $>20.0 \pm 0.0$ & $>20.0 \pm 0.0$ & $>20.0 \pm 0.0$ & $>20.0 \pm 0.0$ & $>20.0 \pm 0.0$ & $8.0 \pm 0.4$ \\
\hline P. vulgaris & $20.0 \pm 0.0$ & $>20.0 \pm 0.0$ & $>20.0 \pm 0.0$ & $>20.0 \pm 0.0$ & $>20.0 \pm 0.0$ & $>20.0 \pm 0.0$ & $1.75 \pm 0.32$ \\
\hline A. baumannii & $13.3 \pm 5.8$ & $16.7 \pm 5.8$ & $>20.0 \pm 0.0$ & $>20.0 \pm 0.0$ & $>20.0 \pm 0.0$ & $>20.0 \pm 0.0$ & $128 \pm 0.48$ \\
\hline B. melitensis & $20.0 \pm 0.0$ & $20.0 \pm 0.0$ & $>20.0 \pm 0.0$ & $>20.0 \pm 0.0$ & $>20.0 \pm 0.0$ & $>20.0 \pm 0.0$ & $1.0 \pm 0.24$ \\
\hline P. aeruginosa & $16.7 \pm 5.8$ & $20.0 \pm 0.0$ & $>20.0 \pm 0.0$ & $>20.0 \pm 0.0$ & $>20.0 \pm 0.0$ & $>20.0 \pm 0.0$ & $2.0 \pm 0.15$ \\
\hline K. pneumoniaee & $20.0 \pm 0.0$ & $20.0 \pm 0.0$ & $>20.0 \pm 0.0$ & $>20.0 \pm 0.0$ & $>20.0 \pm 0.0$ & $>20.0 \pm 0.0$ & $12.0 \pm 0.19$ \\
\hline S. flexneri & $>20.0 \pm 0.0$ & $>20.0 \pm 0.0$ & $>20.0 \pm 0.0$ & $>20.0 \pm 0.0$ & $>20.0 \pm 0.0$ & $>20.0 \pm 0.0$ & $0.75 \pm 0.09$ \\
\hline V. cholerae & $20.0 \pm 0.0$ & $>20.0 \pm 0.0$ & $>20.0 \pm 0.0$ & $>20.0 \pm 0.0$ & $>20.0 \pm 0.0$ & $>20.0 \pm 0.0$ & $1.5 \pm 0.14$ \\
\hline \multicolumn{8}{|l|}{ S. vulgare } \\
\hline S. typhimurium & $1.0 \pm 0.4 \mathrm{~b}$ & $1.5 \pm 1.0$ & $2.1 \pm 0.7$ & $1.7 \pm 0.7$ & $2.1 \pm 0.7$ & $6.7 \pm 2.9$ & $0.5 \pm 0.18$ \\
\hline S. marcescens & $1.0 \pm 0.4 \mathrm{~b}$ & $1.0 \pm 0.4$ & $2.1 \pm 0.7$ & $1.5 \pm 1.0$ & $2.9 \pm 1.9$ & $4.2 \pm 1.4$ & $1.0 \pm 0.15$ \\
\hline E. coli $\mathrm{O}: 157$ & $1.0 \pm 0.4 \mathrm{~b}$ & $1.0 \pm 0.4$ & $1.7 \pm 0.7$ & $1.5 \pm 1.0$ & $3.3 \pm 1.4$ & $6.7 \pm 2.9$ & $8.0 \pm 0.4$ \\
\hline P. vulgaris & $1.5 \pm 1.0 \mathrm{~b}$ & $2.1 \pm 0.7$ & $3.3 \pm 1.4$ & $1.9 \pm 1.1$ & $2.1 \pm 0.7$ & $8.3 \pm 2.9$ & $1.75 \pm 0.32$ \\
\hline A. baumannii & $1.7 \pm 0.7 \mathrm{~b}$ & $2.1 \pm 0.7$ & $2.9 \pm 1.9$ & $2.1 \pm 0.7$ & $4.2 \pm 1.4$ & $8.3 \pm 2.9$ & $128 \pm 0.48$ \\
\hline B. melitensis & $1.0 \pm 0.4 b$ & $1.7 \pm 0.7$ & $3.3 \pm 1.4$ & $2.9 \pm 1.9$ & $4.2 \pm 1.4$ & $10.0 \pm 0.0$ & $1.0 \pm 0.24$ \\
\hline P. aeruginosa & $1.5 \pm 1.0 \mathrm{~b}$ & $2.1 \pm 0.7$ & $3.3 \pm 1.4$ & $2.1 \pm 0.7$ & $4.2 \pm 1.4$ & $10.0 \pm 0.0$ & $2.0 \pm 0.15$ \\
\hline K. pneumoniaee & $1.5 \pm 1.0 \mathrm{~b}$ & $2.1 \pm 0.7$ & $3.3 \pm 1.4$ & $2.1 \pm 0.7$ & $5.0 \pm 0.0$ & $10.0 \pm 0.0$ & $12.0 \pm 0.19$ \\
\hline S. flexneri & $1.7 \pm 0.7 b$ & $2.1 \pm 0.7$ & $3.3 \pm 1.4$ & $2.1 \pm 0.7$ & $3.3 \pm 1.4$ & $10.0 \pm 0.0$ & $0.75 \pm 0.09$ \\
\hline V. cholerae & $1.5 \pm 1.0 \mathrm{~b}$ & $2.1 \pm 0.7$ & $3.3 \pm 1.4$ & $2.1 \pm 0.7$ & $4.2 \pm 1.4$ & $10.0 \pm 0.0$ & $1.5 \pm 0.14$ \\
\hline
\end{tabular}

Comparing the effect of the same solvent by using extracts from different seaweed, methanol is the best solvent:

- using S. vulgare; ap $<0.005$ vs C. tomentosum for K. pneumoniae microorganisms; - using H. musciformis; bp $<0.0005$ vs $S$. vulgare for all microorganisms; $\mathrm{cp}<0.005$ vs $C$. mediterranea for $A$. baumannii microorganisms; $\mathrm{dp}<0.0005$ vs $C$. mediterranea for all microorganisms except $A$. baumannii; ep $<0.005$ vs $C$. tomentosum for E. coli O:157, P. vulgaris and B. melitensis microorganisms; fp $<0.0005$ vs $C$. tomentosum for $S$. flexneri microorganisms. 
exhibited the strongest inhibitory effect with $\mathrm{MIC}_{50}$ of $0.00079,0.00158 \mathrm{mg} / \mathrm{mL}$ against $E$. coli and $P$. aerugenosa bacteria, respectively (Kavita et al., 2014).

Shanmughapriya et al. (2008) investigated inhibitory effects of 14 seaweeds (5 Chlorophyta , 5 Rhodophyta and 4 Phaeophyta) collected from India against 4 gram negative bacterial isolates using methanol:toluene (3:1) and ethanolic extracts. This study revealed that methanol:toluene $(3: 1)$ was the most potent, whereas, ethanolic extracts showed no activity against examined isolates. Among the studied seaweeds, Acrosiphonia orientalis (Chlorophyta) and Stocheospermum marginatum (Phaeophyta) were the most potent by showing the lowest MIC/MBC values 50/10 and 10/0.5 $\mathrm{mg} / \mathrm{mL}$, respectively against $P$. aeruginosa isolate.

Recently, Sushanth and Rajashekhar (2015) reported the ethanol, methanol and hexane extracts antimicrobial activity of 4 microalgae against 4 gram-negative bacterial strains. This investigation revealed that the ethanol Skeletonema costatum extract displayed the lowest MIC value of $0.5 \mathrm{mg} / \mathrm{mL}$ against $K$. pneumoniae. Whereas, the highest MIC was recorded to be $2 \mathrm{mg} / \mathrm{mL}$ (this value varied according to the tested solvent, bacteria isolate and microalgae species) while, hexane extracts of $S$. costatum exhibited a moderate activity with MIC of $1 \mathrm{mg} / \mathrm{mL}$ against $S$. typhimurium isolate.

More recently, Alves et al. (2016) reported that the seaweed inhibitory effect as expressed by MIC were $12.5 \mathrm{mg} / \mathrm{mL}$ with methanolic $S$. polyceratium extracts against both $E$. coli and $K$. pneumoniae isolates that estimated $\mathrm{MBC}$ values were recorded to be 50 and 12.5 $\mathrm{mg} / \mathrm{mL}$ against $E$. coli and $K$. pneumoniae isolates, respectively.

\section{Conclusion}

Antibacterial activities of seaweeds were screened based on $\mathrm{ZI}, \mathrm{MIC}_{50}$ and $\mathrm{MBC}$ values using water and six solvents. Aqueous seaweed extracts showed no activity against all isolates regardless examined seaweed species. Data presented here depicted that the methanolic and hexane extracts of S.valgare were the most potent by showing the lowest $\mathrm{MIC}_{50}$ values of $0.08 / 1 \mathrm{mg} / \mathrm{mL}$ (against $S$. flexneri and E. coli O:157 isolate) and the lowest MBC value of $1.00 / \mathrm{mL}$ (methanolic extract $S$. typhimurium, S. maccens, E. coli $\mathrm{O}: 157$ and B. melitensis isolates and also with ethanolic extract against S.maccens and $E$. coli $\mathrm{O}: 157$ isolates. Overall, standard antibiotic was more potent than seaweeds crude extracts against tested bacterial isolates regardless examined solvents. Based upon data presented herein, it is important to investigate the inhibitory effect of purified bioactive constituents of $S$. vulgare extracts as a potential source for antibacterial pretreatment.

\section{Acknowledgement}

We thank Dr. I. Othman (Director General of AECS) and Dr. N. MirAli (Head of Molecular Biology and Biotechnology Department in AECS) for their support, and also the Plant Biotechnology Group for technical assistance.

\section{References}

Alves, R.C., das Merces, P.F.F., de Souza, I.R.A, de Almeida, C.M.A., da Silva, A.P.S.A., Lima, V.L.de M., Correia, M.T.dos S., da Silva, M.V., da Silva, A.G. 2016. Antimicrobial activity of seaweeds of Pernambuco, northeastern coast of Brazil. African Journal of Microbiology Research, 10: 312-318.

Bauer, A.W., Kirby, W.M., Sherris, J.C., Turck, M. 1966. Antibiotic susceptibility testing by a standardized single disc method. The American Journal of Clinical Pathology, 45: 493-496.

Boujaber, N., Oumaskour, N., Hassou, N., Lakhdar, F., Assobhei, O., Etahiri, S. 2016. Antimicrobial effect of two marine algae Gelidium sesquipedale and Laminaria ochroleuca collected from the coast of El Jadida-Morocco. Journal of Bio Innovation, 5: 16-23.

Boyd, R.F. 1995. Basic Medical Microbiology. 642 pp, $5^{\text {th }}$ edition. Little Brown and Company, Boston, USA.

Chandrasekaran, M., Venkatesalu, V., Raj, G.A., Krishnamoorthy, S. 2014. Antibacterial properties of various extracts of Sargassum wightii against multidrug resistant bacterial strains. Phykos, 44: 17-28.

Chiao-Wei, C., Siew-Ling, H., Ching-Lee, W. 2011. Antibacterial activity of Sargassum polycystum C. Agardh and Padina australis Hauck (Phaeophyceae). African Journal of Biotechnology, 10: $14125-14131$.

Elnabris, K.J., Elmanama, A.A., Chihadeh, W.N. 2013. Antibacterial activity of four marine seaweeds collected from the coast of Gaza Strip, Palestine. Mesopotamian Journal of Marine Science, 28: 8192.

Ibtissam, C., Hassane, R., José, M.L., Francisco, D.S.J., 
Antonio, G.V.J., Hassan, B., Mohamed, K. 2009. Screening of antibacterial activity in marine green and brown macroalgae from the coast of Morocco. African Journal of Biotechnology, 8: 1258-1262.

Jawetz, E., Mellnick, J.L., Adelberg, E.A. 1985. Review of Medical Microbiology, pp. 139-218. $20^{\text {th }}$ edition. Applellation Lange Norwalk, Connecticut, USA.

Jeyaseelan, E.C., Kothai, S., Kavitha, R., Tharmila, S., Thavaranjit, A.C. 2012. Antibacterial activity of some selected algae present in the coastal lines of Jaffna Peninsula. International Journal of Pharmaceutical and Biological Archives, 3: 352-356.

Kandhasamy, M., Arunachalam, K.D. 2008. Evaluation of in vitro antibacterial property of seaweed of southeast coast of India. African Journal of Biotechnology, 7: 1958-1961.

Karthick, P., Mohanraju, R., Kada, N.M., Ramesh, C. 2015. Antibacterial activity of seaweed collected from South Andaman, India. Journal of Algal Biomass Utilization, 6: 33-36.

Kausalya, M., Rao, G.M.N. 2015. Antimicrobial activity of marine algae. Journal of Algal Biomass Utilization, 6: 78- 87.

Kavita, K., Singh, V.K., Jha, B. 2014. 24-branched delta 5 sterols from Laurencia papillosa red seaweed with antibacterial activity against human pathogenic bacteria. Microbiological Research, 169: 301-306.

King, L.B., Swiatlo, E., Swiatlo, A., McDaniel, L.S. 2009. Serum resistance and biofilm formation in clinical isolates of Acinetobacter baumannii. FEMS Immunology and Medical Microbiology, 55: 414421.

Leven, M.M. 1987. Escherichia coli that causes diarrhea: Enterotoxigenic, enteropathogenic, enteroinvasive, enterohemorrhagic and enteroadherent. The Journal of Infectious Diseases, 155: 377-389.

Pérez, M.J., Falqué, E., Domínguez, H. 2016. Antimicrobial action of compounds from marine seaweed. Marine Drugs, 14: 1-38.

Rhimou, B., Hassane, R., José, M., Nathalie, B. 2010. The antibacterial potential of the seaweeds (Rhodophyceae) of the Strait of Gibraltar and the
Mediterranean coast of Morocco. African Journal of Biotechnology, 9: 6365-6372.

Ríos-Dueñas, E., Rodríguez-Avial, I., Picazo, J.J. 2011. In vitro activity of ceftobiprole and seven other antimicrobial agents against invasive Streptococcus pneumoniaee isolates in Spain. The European Journal of Clinical Microbiology and Infectious Diseases, 30: 1621-1625.

Saleh, B., Hammoud, R., Al-Mariri, A. 2015. Antimicrobial activity of Ficus sycomorus L. (Moraceae) leaf and stem-bark extracts against multidrug resistant human pathogens. Herba Polonica, 61: 39-49.

Shanmughapriya, S., Manilal, A., sujith, S., Selvini, J., Kiran, G.S., Natarajaseenivasan, K. 2008. Antimicrobial activity of seaweeds extracts against multiresistant pathogens. Annals of Microbiology, 58: $535-541$.

Shareef, K., M., Sridharan, M.C., Abdul Nazar, Y. 2012. Antibacterial activity of marine red alga Hypnea musciformis. Journal of Chemical and Pharmaceutical Research, 4: 5098-5100

Srinivasan, V.B., Rajamohan, G., Gebreyes, W.A. 2009. Role of AbeS, a novel efflux pump of the SMR family of transporters, in resistance to antimicrobial agents in Acinetobacter baumannii. Antimicrobial Agents and Chemotherapy, 53: 5312-5316.

Sushanth, V.R., Rajashekhar, M. 2015. Antioxidant potential of eight species of cyanobacteria isolated from Arabian Sea coast of Karnataka. Journal of Chemical and Pharmaceutical Research, 7: 938942

Tajbakhsh, S., Ilkhani, M., Rustaiyan, A., Larijani, K., Sartavi, K., Tahmasebi, R., Asayesh, G. 2011. Antibacterial effect of the brown alga Cystoseira trinodis. Journal of Medicinal Plants Research, 5: 4654-4657.

Zbakh, H., Chiheb, H., Bouziane, H., Sánchez, V.M., Riadi, H. 2012. Antibacterial activity of benthic marine algae extracts from the Mediterranean coast of Morocco. The Journal of Microbiology, Biotechnology and Food Sciences, 2: 219-228. 